\title{
Circuit
}

Musiques contemporaines

CIRCUIT

\section{Strange yet Familiar Sounds in Zosha Di Castri's String Quartet \\ No. 1}

\section{Des sons étranges et pourtant familiers dans le Quatuor à cordes $n^{0} 1$ de Zosha Di Castri}

\section{Landon Morrison}

Volume 28, numéro 2, 2018

URI : https://id.erudit.org/iderudit/1051294ar

DOI : https://doi.org/10.7202/1051294ar

Aller au sommaire du numéro

Éditeur(s)

Circuit, musiques contemporaines

ISSN

1183-1693 (imprimé)

1488-9692 (numérique)

Découvrir la revue

Citer cet article

Morrison, L. (2018). Strange yet Familiar Sounds in Zosha Di Castri’s String Quartet No. 1. Circuit, 28(2), 83-98. https://doi.org/10.7202/1051294ar
Résumé de l'article

Cet article propose une analyse détaillée du Quatuor à cordes $n^{0} 1$ de Zosha Di Castri (2016), inscrivant cet opus en relation avec l'oeuvre encore jeune de cette compositrice et démontrant comment sa forme, pourtant compacte, parvient néanmoins à contenir des éléments d'une grande variété stylistique. Le concept de défamiliarisation, emprunté à la critique littéraire, fournit une base théorique utile pour comprendre la pièce. En présentant des éléments musicaux familiers dans des contextes nouveaux et étranges, Di Castri contourne habilement les modes habituels de la réception et encourage l'auditeur à s'engager activement vis-à-vis l'oeuvre aux multiples codes. Cette revivification de la conscience perceptuelle s'accomplit à travers l'utilisation d'un certain nombre de techniques compositionnelles, incluant la juxtaposition ou la superposition de matériaux musicaux contrastants, la transformation de motifs et la distorsion de la syntaxe formelle. Considérées dans leur ensemble, ces méthodes de défamiliarisation génèrent une intervention stylistique qui subvertit les normes compositionnelles de façon ludique, permettant à Di Castri de faire un pas décisif dans le développement de son propre style musical. 
CAHIER D'ANALYSE

\section{Strange yet Familiar Sounds in Zosha Di Castri’s String Quartet No. 1}

Landon Morrison

\section{Introduction}

In her String Quartet No. 1 (2016), Canadian composer Zosha Di Castri (b. 1985) demonstrates a unique ability to navigate musical extremes. Lightning-fast passagework alternates with slow, glacial textures. Idiomatic folk tunes rub against abstract melodies. Impressionistic harmonies are inflected with warped microtonal tunings. And conventional playing methods are deployed alongside an imaginative use of instrumental techniques, mimetic gestures, and technological tropes. Taken together, these diverse stylistic markers yield a chimeric sound world that defies easy categorization, jolting the listener out of passivity and into a deeper engagement with the music's multi-coded logic.

Looking back at Di Castri's still-nascent œeuvre, one finds clear precedents for many of the underlying currents in String Quartet No. 1. Already in her early works, such as Cortège (2010) and La forma dello spazio (2010), one encounters sharp juxtapositions of block textures moving at different speeds, as well as a rich palette of harmonies that bear the markings of a post-spectral sensibility for sound. Other works, such as Phonotopographie (2012), make explicit references to folk music, establishing an ongoing interest in blending vernacular elements into abstract musical settings. And finally, pieces such as The Phonograph (2014), Phonobellow (2015), and Tachitipo (2016) address the cultural impact of outmoded technologies, pointing to a reflexive engagement with media history in the composer's recent practice. ${ }^{1}$ Against the backdrop of these previous works, String Quartet No. 1 can be heard as an encapsulation of ideas that have gradually moved to the center of Di Castri's æsthetic over the course of several years. But the quartet also diverges from
1. It is perhaps a telling coincidence that these three pieces speak to the historical import of the phonograph, the high-speed camera, and the typewriter (respectively), a combination that bears more than passing resemblance to the title of Friedrich Kittler's seminal book in the field of media theory: Gramophone, Film, Typewriter (1999) 
2. Shklovsky, 1917, p. 12. According to Shklovsky, common defamiliarizing devices in literature include: adopting an unusual narrative perspective, mixing literary and colloquial speech, interleaving foreign languages, and conflating the real with the fantastical.

3. Ibid., pp. 12-13.

4. For example, see Piotr Grella-Możejko's application of defamiliarization to the music of Helmut Lachenmann (2005, pp. 57-75), and also Lachenmann's own comments, which hint at his affinity for defamiliarization: "where perception thus penetrates into the structure of the familiar, the familiar becomes foreign once again... [and] as the perceiver radically renews his relation to what was previously familiar, he himself changes" (2003, p. 30).

5. Brecht, 1936, pp. 96-98.

6. Kristeva, 1973, p. 29. these previous compositions in its sheer condensation of heterogeneous elements into a compact, capsule form. Lasting roughly ten minutes, the quartet captures maximal variety in minimal space, and it does so in a way that often foregrounds differences between contrasting materials. The result is a mercurial piece of music that challenges listeners to make sense of its eclectic stylistic impulses and rapid shifts in character.

From a purely æsthetic perspective, the quartet's presentation of common musical figures outside of their usual contexts suggests the possibility of understanding the work through the concept of defamiliarization. As described by the Russian literary theorist Viktor Shklovsky, defamiliarization (from the Russian ostranenie, literally "making strange") refers to a set of formal devices designed to "remove objects from the automatism of perception." ${ }^{2}$ Shklovsky argues that the unrelenting routine of everyday life elicits readymade reactions, so it becomes the goal of the artist to short-circuit these entrenched modes of reception, "pricking the conscience... [so] that one may recover the sensation of life." 3 While Shklovsky used defamiliarization as a means for distinguishing between "ordinary" and "poetic" speech, the basic premise behind the concept is entirely amenable to musical applications. ${ }^{4}$ Indeed, in the case of Di Castri's quartet, defamiliarization provides a useful theoretical basis for thinking about how the piece rearticulates familiar musical objects within the context of a new sonorous environment.

Beyond Shklovsky's formalist conception of defamiliarization, there is an implicit social and political dimension that can be read into the concept. As musical objects are distanced from their ordinary contexts, so too are listeners distanced from their habitual modes of reception, and this double estrangement opens up space for contemplating the constructed (and therefore contestable) nature of established systems. In this sense, defamiliarization has the potential to incite change by subverting naturalized languages and modes of discourse, be they musical or otherwise. This more politicized form of defamiliarization as a kind of artistic intervention is most often associated with Bertolt Brecht's Verfremdungseffekt, or "distancing effect," which infuses Shklovsky's ideas with Marxist overtones and adapts them for use in a theatrical setting. ${ }^{5}$ For the purposes of the present study, however, I will sideline Brecht in order to forge a more distant connection between Shklovsky's concept of defamiliarization and Julia Kristeva's theory of a "speaking subject" who, by manipulating the slippage of meaning inherent in any signifying process, can stage a "transgression of systematicity." While the links between Shklovsky and Kristeva may not be immediately apparent, both writers locate the unique disposition of the poetic word in its ability to deviate from 
the grammatical rules of ordinary language. ${ }^{7}$ But for Kristeva, this poetic deviation doesn't just spark an æsthetic appreciation of the text: it destabilizes systems of power and critiques ideologies, allowing the speaking subject to remake the extant social order within which he/she is invariably caught up. For this reason, Kristeva's dialogic reformulation of poetic processes provides an alternative basis for hearing Di Castri's string quartet as a playful subversion of compositional norms, rather than mere æsthetic adventurism.

In what follows, Shklovsky's approach to defamiliarization provides a loose frame of reference for examining the radical recontextualization of materials within Di Castri's string quartet. I deploy the concept as a means for describing three types of musical scenarios. In the first, contrasting materials are either juxtaposed side-by-side or superimposed on top of each other, causing them to become dislodged from their original contexts by virtue of their close proximity. In the second, musical themes become increasingly unrecognizable as they are subjected to processes of transformation such as fragmentation, pitch alteration, temporal expansion, and other forms of variation. And in the third, the work's fractious contours produce a distortion of formal syntax, subverting the listener's expectations via the insertion of nonlinear digressions, detours, and parenthetical asides. All three of these scenarios can be viewed as musical analogues to Shklovsky's defamiliarization concept because, like his literary devices, they frustrate one's ability to passively grasp the æsthetic experience. My analysis examines several of these devices in the quartet before considering the effect of defamiliarization on the work's semiotic disposition. Drawing on Kristeva, I argue that the quartet engages in a kind of carnivalesque discourse, in which the mingling of musical opposites blurs distinctions between high and low, fact and fiction. Moving from Shklovsky's formalism to Kristeva's semiotics, the article offers a bi-focal perspective that sheds light on the interaction of structural and semantic elements in Di Castri’s String Quartet No. 1.

\section{Overview of String Quartet No. 1}

Conceived as a commission for the $12^{\text {th }}$ Banff International String Quartet Competition (2016), Di Castri's score is technically demanding for the performers, requiring them to master a variety of virtuosic feats and instrumental techniques. ${ }^{8}$ At the same time, Di Castri grants the performers a considerable amount of flexibility in passages marked "freely," "quasi-improvisatory," and "aleatoric." The loosening of compositional control at these moments ensures that the work's personality will vary considerably depending on the ensemble's interpretive choices, a fact borne out by the ten back-to-back
7. For Kristeva, these poetic deviations from ordinary language include the presence of articulatory effects, multiple meanings, syntactic irregularities, and primary processes such as displacement, condensation, and metaphor (1973, pp. 28-29).

8. Di Castri's String Quartet No. 1 was featured during the Canadian Commission Round of the Banff competition, which took place August 29-September 4, 2016. Performances of the work can be viewed online at the BISQC YouTube channel. Along with BISQC, the quartet was co-commissioned by The Canadian Broadcasting Company and the Americas Society. 
9. Along with String Quartet No. 1 (JACK Quartet), the album will feature several other works by Di Castri, including The Animal After Whom Other Animals Are Named (Ekmeles), Cortège (Talea Ensemble), Dux (Julia Den Boer), La forma dello spazio (International Contemporary Ensemble), how many bodies have we to pass through (Diego Espinosa Cruz Gonzalez), and Tachitipo (Yarn/Wire). Works for large ensemble will be conducted by Lorraine Vaillancourt, and the entire project will be produced by Martha de Francisco at Oktaven Audio recording studio in Mount Vernon, NY.
10. On this point, the quartet's form recalls Shklovsky's discussion of Laurence Sterne's Tristram Shandy (1759), in which the narrative device is "laid bare" by a series of disruptions and digressions (1921, p. 27).

11. Cameron, 2008, pp. 20-25. performances of the work during the Banff competition. Since its premiere, Di Castri's quartet has been played throughout North America and Europe; in particular, the Rolston Quartet, which won first prize at Banff, has made the work a staple of its concert repertoire. And looking ahead, prospects for the work's continued visibility are promising, as it is slated to be recorded by the renowned JACK Quartet for an album that will be released later this year on the New Focus Recordings label. ${ }^{9}$

Shown in Figure 1, Di Castri's string quartet exhibits a cyclical design that can be represented by the seemingly straightforward formal scheme: A-B-C-B'-A' (codetta). The symmetry of this pattern is obscured, however, by the fact that each of the thematic returns is significantly varied, making it difficult to establish clear-cut, over-arching relationships between the work's different sections. The formal trajectory is further complicated by a short refrain (labeled $R$ in Figure 1 ) that needles its way into each section of the work, with the sole exception of Section B'. This highly mobile refrain acts as a parenthetical insertion, breaking up the musical surface and disrupting any sense of a simple linear progression. As a result, the work's form fissures into two layers of articulation, in which the larger sections remain relatively cohesive, while the foreground fractures into a disjunct sequence of self-contained modules. Within this foreground level, teleology is skewed by a schismatic phrase structure, laying bare the work's structural seams and allowing the listener to appreciate its patchwork assembly.

Linking back to the use of defamiliarization devices in literature, we can understand Di Castri's discontinuous approach to form as comparable to that of a narrator who exposes his/her own role in constructing the storyline. ${ }^{10}$ Or, from the vantage point of another medium, we might compare the quartet's form to the modular temporal schemes of contemporary cinema. As described by Allan Cameron, these modular designs foreground the "formal articulation of narrative temporality... [so that the] syntagmatic structure of the plot seems dictated by external forces rather than motivated by internal demands of the story." ${ }^{\prime 1}$ In both literary and cinematic contexts, the distortion of linear time calls attention to the story's artificial construction by an

FIGURE 1 Form Diagram for String Quartet No. 1

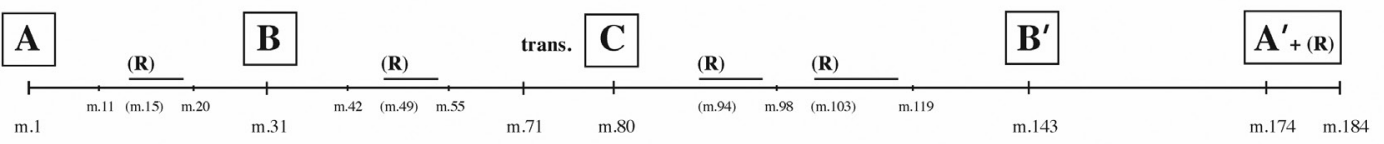


outside source. And while the formal development of music lacks the same kind of specificity that one finds in concrete narratives, it is still possible to hear the structure of Di Castri's quartet as marked by similar discontinuities, highlighting the role of the composer's hand in arranging and rearranging the work's constituent parts. ${ }^{12}$

\section{Section A, mm. 1-30}

As shown in Figure 2, the beginning of the quartet is marked by an explosive gesture-a screeching rush of noise that quickly plummets from the heights of the first violin to a low, sustained $\mathrm{C}$ in the cello. This initial outburst is followed by two types of material that immediately establish the work's capacity for staging extreme contrasts. On the one hand, there is a sustained harmony in mm. 2-3 that progresses slowly, allowing the performers ample time to shape the sound with dynamic swells, gradual glissandi, and subtle timbral shifts (e.g., sul ponticello to molto sul ponticello, and senza vibrato to molto vibrato). On the other hand, there is a high-pitched melody in the second violin (mm. 4-5) that introduces a rapid tremolo articulation meant to imitate "chatter, like fast-forwarded speech." With these instructions calling on the performer to imitate a technologically mediated sound, Di Castri veers into the mimetic realm of technomorphism, establishing one of the work's central tropes. ${ }^{13}$ This particular incarnation of the trope-that
12. Additional support for a modular view of the quartet's form can be found in Di Castri's assertion that, since she began using digital audio workstations (e.g., Logic Pro) as a medium for sketching formal mock-ups, she has "stopped trying to compose pieces in linear order... [instead] jumping between sections and ideas" (2014, p. 26). Hence, there is a connection between the visual representation of sound files as moveable modules within a DAW interface and Di Castri's conception of musical form as a series of interchangeable modules.

13. While still largely undertheorized, several authors have identified technomorphism as an important characteristic of spectralism. For instance, see Peter Niklas-Wilson's discussion of ring modulation as a source of harmonic generation in Gérard Grisey's Partiels (1989, pp. 40-41), or more recently, Philippe Leroux's self-reflexive account of using technomorphic models in his work Voi(Rex), including techniques for filtering, spectral freezing, and frequency shifting (2006, pp. 161-162).

FIGURE 2 Section A, mm. 1-5

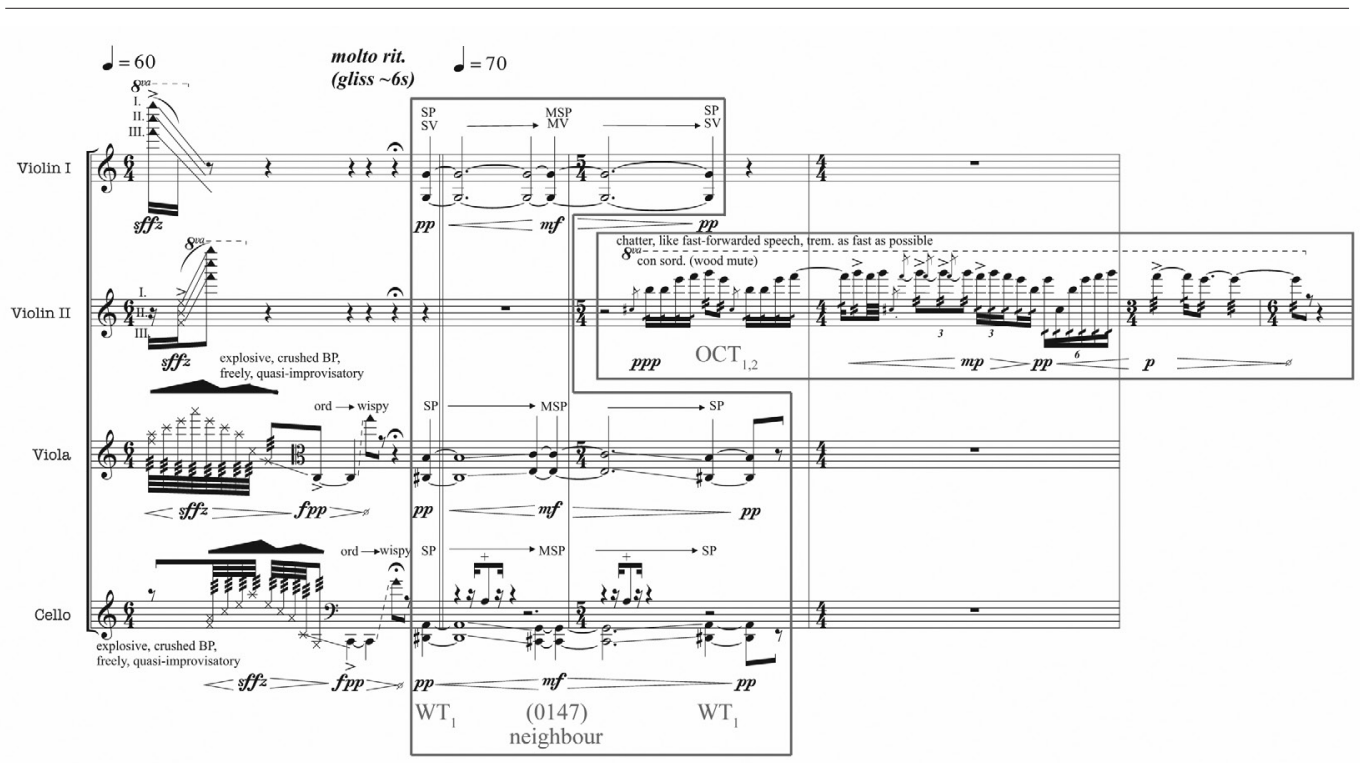


14. Gérard Grisey, 2008, p. 159.

15. In this analysis, I will label pitch collections using the conventions laid out in Joseph Straus's textbook, Introduction to Post-Tonal Theory. Whole tone collections are designated as "WT" with either a o or 1 subscript; octatonic collections are labeled as "OCT" with a subscript of either 0-1, $1-2$, or 2-3, indicating the pitch classes where the semitone falls within the collection. See Straus, 2005, pp. 144147.

16. According to Kramer, multiplydirected time applies to musical situations where the "adjacent middle ground implications are ignored in favor of larger time spans: a section's nature depends on previous but not immediately adjacent music" (1981, p. 554). of "fast-forwarded" speech-provides an extreme counterweight to the slow harmonies in mm. 2-3. Indeed, when heard against the grain of the violin's fast-forwarded melody, the sluggish pace of the preceding harmonies is suggestive of an artificial time-stretching technique such as the phase vocoder. The extreme opposition between these time scales places them at either end of a vast temporal continuum, recalling Gérard Grisey's differentiation between stretched time ("the time of whales") and contracted time ("the time of birds and insects"), both distinct from the familiar time of "human language and respiration." ${ }^{14}$

Beyond their antonymic temporal dispositions, these two blocks of material are further distinguished by their contrasting pitch content. In mm. 2-3, a prolonged whole tone harmony $\left(\mathrm{WT}_{1}\right)$ frames an interior neighbour motion to pitch-class set (0147), while the second violin's unaccompanied melody in mm. 4-5 exhibits an altogether different pitch profile. ${ }^{15}$ At first hearing, the melody suggests a Phrygian character due to its strong perfect fourth motion from B up to $\mathrm{E}$, as well as its repeated semitonal resolutions from $\mathrm{F}$ down to $\mathrm{E}$. But this interpretation is called into doubt by the repeated C-sharp grace notes, which signal that the melody may instead be heard as a subset of the octatonic collection $\left(\mathrm{OCT}_{1,2}\right)$. Although its representation here is subtle, octatonicism takes on a more significant role as the work progresses and, in retrospect, it becomes clear that the opposition between whole tone and octatonic pitch collections in mm. 2-5 foreshadows a long-range juxtaposition of these two modalities at the highest levels of the quartet's structure.

The importance of the excerpt shown in Figure 2 cannot be overemphasized. With the weight of a Schoenbergian Grundgestalt, the quartet's opening bars present the germinal seeds for nearly all of the work's heterogeneous materials. Multi-stop screeches, glissandi, tremolos, dynamic swells, pizzicati-the condensed presentation of these varied articulations and sound characters in mm. 1-5 provide the basic building blocks for most of the other themes in the work. And with regard to the modular form described above, the stark contrast between different temporalities in the work's opening phrase immediately shatters any sense of straightforward linearity, foreshadowing the quartet's preoccupation with what Jonathan Kramer might describe as "multiply-directed time."16 In short, the quartet's opening acts as a microcosm of the entire piece, priming the listener for what's to come by presenting an unmitigated, side-by-side display of extreme oppositions: slowfast, low-high, loud-soft, noise-silence, harmonic-melodic, sustain-tremolo, whole tone-octatonic, group-solo, and close-distant. 
Moving ahead, Figure za shows the beginning of the work's second phrase (mm. 11-14), at which point the whole-tone harmony from mm. 2-3 returns (sans glissando) and is paired with a "folky" theme in the second violin. If, in the previous example, contrasting characters alternated in a stop-and-go fashion (juxtaposition), here they are collapsed into a simultaneity that blurs traditional distinctions between high and low æsthetics (superimposition). The folk material is clearly recognizable as such, but it has been estranged from its usual context and immersed within a largely abstract discourse, igniting a process of defamiliarization that plays out in a few important ways. First, the violin's repeated stepwise motion from D up to $G$ firmly establishes a tonal centricity around $\mathrm{G}$ major, adding a veneer of diatonicism onto the underlying whole tone harmony. Second, the folk tune appears to be incomplete and stripped of any unique identifying marks. What begins as a boisterous fiddle riff quickly drifts away, imbuing the passage with an air of nostalgia, as though a melodic snippet had momentarily bubbled up from the depths of one's memory only to disappear again. This fragmentary aspect reinforces the work's open-ended nature, in which seemingly incompatible elements from different cultural spheres merge in a pseudo-surrealist fashion. And third, after only two measures, the folk material recedes into a sustained texture that bifurcates into two streams: the lower strings continue to prolong a whole tone harmony before sliding back to set class (0147), while the upper strings instigate a microtonal "warping" effect that is reminiscent of Italian composer Giacinto Scelsi's tone-splitting technique. ${ }^{17}$ This striking effect occurs when the violins coalesce around a focal pitch $(\mathrm{G}, \mathrm{m} .13)$ and begin amassing a cluster of near-unison pitches; in this case, F-sharp, G-quartersharp, G-sharp, and G-three-quarters-sharp. By combining whole tone harmonies with diatonicism and microtonality, the passage creates a dreamy, disorienting atmosphere that amplifies the already strange appearance of a folky trope in the midst of an abstract setting.

The folk theme returns at two other points in the quartet-once at the beginning of the work's third phrase ( $\mathrm{mm} .20-21$, shown in Figure $3 \mathrm{~b}$ ), and again at the end of Section B (mm. 68-70, shown in Figure 3c). At each return, the material is transformed through a developing variation procedure that gradually obscures its original identity. At mm. 20-21, the entire thematic complex is transposed upwards by a perfect fifth, placing the folk theme in the key of $\mathrm{D}$ major and shifting the harmony from a $\mathrm{WT}_{1}$ to a $\mathrm{WT}_{\circ}$ collection. Aside from these minor changes, however, the first variation of the folk theme maintains an obvious relation to its initial presentation. By contrast, the final reprise of the folk material is distorted in a more radical manner.
17. In the performance instructions of the score, Di Castri distinguishes between two main approaches to microtones in the work: 1) "warping... as a kind of ornamentation or inflection of the main tempered pitch," and 2) "melodically, as part of a microtonal mode." 
FIGURE 3A Section A, mm. 11-14

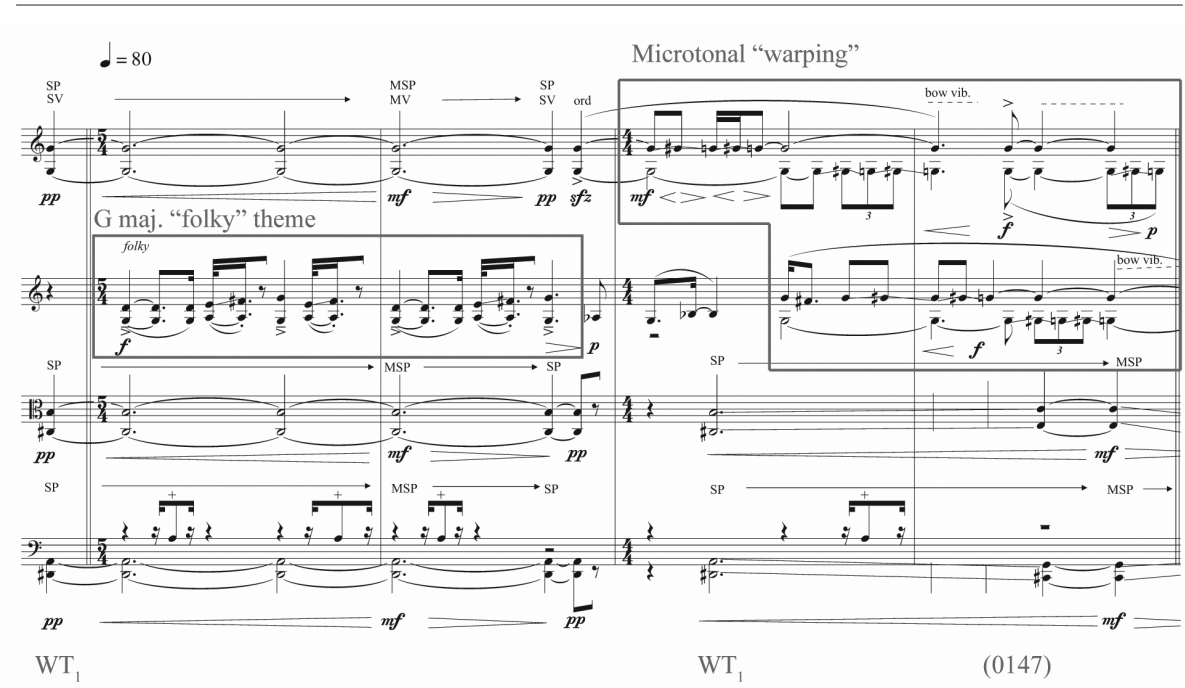

FIGURE 3B Section A, mm. 20-21

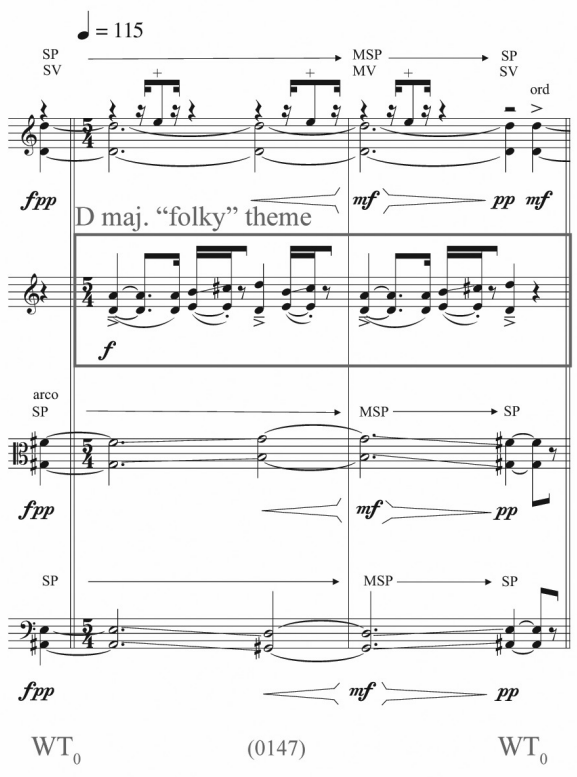

Figure 3C Section B, mm. 68-70

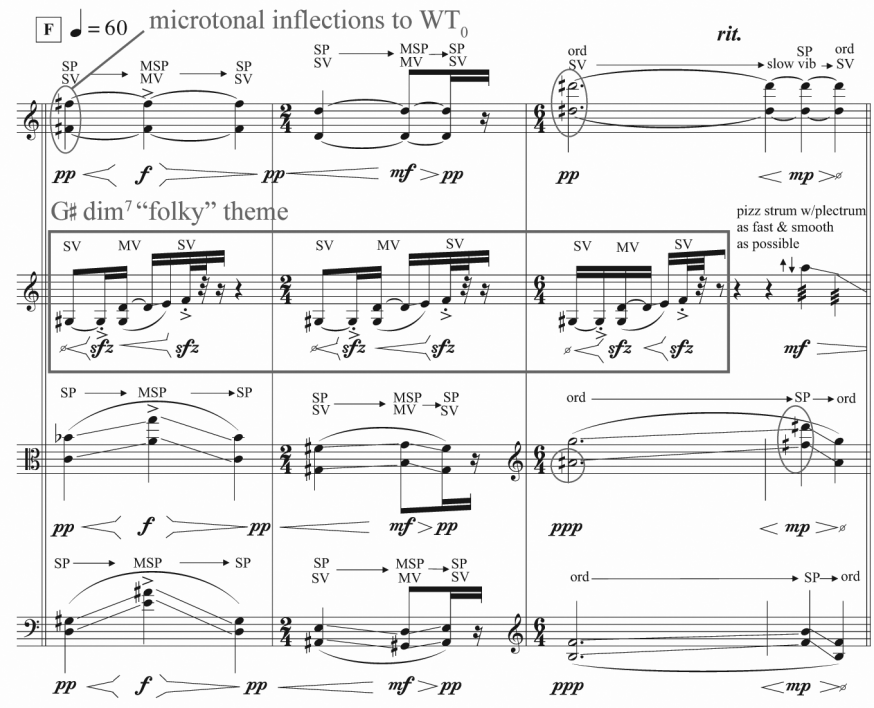

$\mathrm{WT}_{0}$ (0356) $\mathrm{WT}_{0} \quad \mathrm{WT}_{0}$ (0147) $\mathrm{WT}_{0} / / \quad \mathrm{WT}_{1}+$ microtonal inflections 
Shown in Figure ${ }_{3} \mathrm{C}$, the tune is substantively reconfigured so that, instead of outlining a simple cadential motion to tonic, it invokes a fully diminished seventh chord built on G-sharp. In addition, its articulation has changed such that two crescendi from niente to sforzando now bisect the gesture, fracturing its continuity. ${ }^{18}$ And finally, there have been significant changes to the sustained accompaniment that envelopes the folk theme, such that the prolongation of the underlying whole tone collection $\left(\mathrm{WT}_{\mathrm{o}}\right)$ is inflected with the addition of a microtonal pitch in the first violin (F-quarter-sharp), and the interior glissandi move at twice the original speed. The combined effect of these changes distorts the passage so that its "folkiness" becomes fully submerged within the quartet's prevailing abstraction. Zooming outward, a backto-back comparison of the folk theme's evolution over the course of these three iterations (Figures $3 \mathrm{~A},{ }_{3} \mathrm{~B}$, and ${ }_{3} \mathrm{C}$ ) provides a clear illustration of how musical objects are defamiliarized in the quartet through the use of transformational processes such as motivic variation and harmonic recontextualization.

It's worth noting that one finds references to folk music in several of Di Castri's earlier works. In some cases, such as the aforementioned Phonotopographie, the reference remains recognizable, realistic, and relatively self-contained. But in other works, the folk content is gradually obscured using techniques similar to those found in the quartet. For instance, the orchestral work Lineage (2013) features the progressive transformation of a "microtonal chorale" which, according to Di Castri, is "loosely inspired by the haunting, intermittent, melancholy singing of Ukrainian/Greek Catholic burial ceremonies."19 Part invention and part transcription, this exploration of fictive culture is an example of what Di Castri calls "faux-folk" music, a genre that lures the listener into a vernacular frame of reference with illusory representations of folk music. ${ }^{20}$

At the beginning of Section B (mm. 31-34, shown in Figure 4a), the sustained whole tone harmonies of the work's opening yield to a "pointillistic" texture, preparing the way for a secondary theme that begins at m. 35. Like atomized dots in an impressionist painting, the staggered entrances of individual pitch nodes within this luminescent texture coalesce into a composite harmony. At first, they appear to articulate an E dominant seventh chord with an added minor ninth (F), but the fixed G-sharp and $\mathrm{F}$ in the cello tilt the quality towards a fully-diminished seventh sonority (the same harmony expressed by the second violin at mm. 68-70, shown in Figure 3c). The only outlier from this chord is the G-natural in the viola in $\mathrm{m} .3^{1}$, and while this is just one node within an otherwise stable network of pitches, its inclusion warrants further consideration. When the $\mathrm{G}$ is incorporated as part of the
18. The altered harmonic and articulative aspects of this passage are derived from the beginning of Section B (mm. 31-34, shown in Figure 4), so the final statement of the folk theme actually absorbs the harmonic influence of the work's intervening material, blending material from Sections $A$ and $B$.

19. Incidentally, Lineage is a sister work to Phonotopographie - the former is a substantial reworking of the latter, with new material added. For a discussion of the relationship between these two works, see Di Castri, 2014, pp. 14-17.

20. A more extreme example of this approach can be found in Di Castri's work Serafiniana (2014), which she describes in the program note as a "surrealistic sonification of Luigi Serafini's Codex Serafinianus." The reference here is to Luigi Serafini's illustrated encyclopedia for an imaginary world of strange creatures and customs (Serafini, 1981). Di Castri's treatment of Serafini's fantastical text provokes a bizarre kind of double fake-ness, in which the sense of musical estrangement is amplified by its association with "faux-folkloric" literature. 
Sections $B$ and $B^{\prime}, \mathrm{mm} \cdot 31-70$ and $\mathrm{mm} \cdot 143-73$

FIGURE 4A Section B, mm. 31-34.

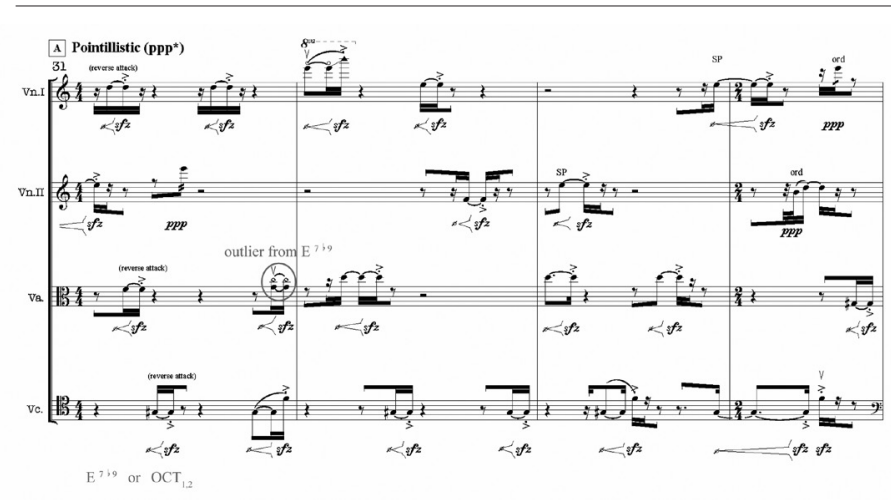

FIGURE 4B Section B', mm. 143-147.

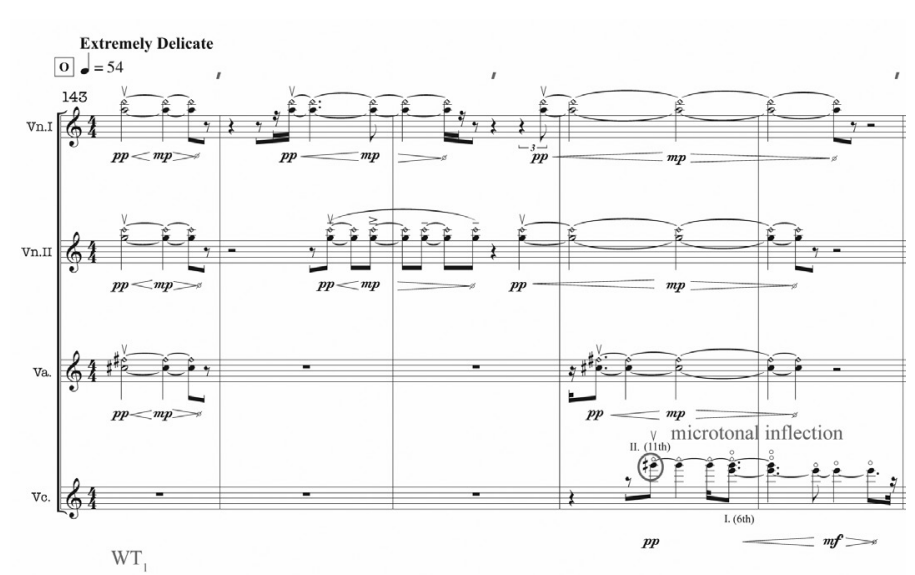

harmonic field, the passage takes on an octatonic character $\left(\mathrm{OCT}_{1,2}\right)$, signaling a shift from the predominantly whole tone sonorities of Section A to the octatonicism of Section B (especially evident in the secondary theme shown in Figure 5).

The excerpt in Figure 4a is also notable for its inclusion of another technomorphic trope: a "reversed attack" that is based on the manipulation of a sound's morphological profile. According to the performance instructions in the score preface, each of the pitches should be articulated with a special bowing technique that mimics the sound of a "guitar attack played backwards." ${ }^{21}$ Because the sound of a plucked guitar string possesses an archetypal 
amplitude envelope (i.e., initial peak to gradual decay), an approximate simulation of the sound's reversal requires that the performers begin softly, quickly crescendo to sforzando, and end with a sharp, nearly crunched release. Considered in conjunction with the stunted duration of these pitches, the aural effect is that of a sampled audio fragment being reversed and then temporally compressed. The passage harkens back to the "fast-forwarded" melody in $\mathrm{mm} .4-5$, providing more evidence that technomorphism is an important compositional model in the quartet.

Skipping ahead, the pointillistic texture from $\mathrm{mm}$. 31-34 returns in Section B' (m. 143), at which point its shape is dramatically altered (see Figure 4b). The passage begins with a whole-tone trichord that can be heard as a faint, transposed echo of the $\mathrm{E}$ dominant seventh sonority in $\mathrm{mm}$. 31-34, but after only a few measures, this harmony is inflected with a microtonal alteration (G-quarter-sharp), instigating motion elsewhere through a series of nebulous tertian harmonies. The passage also maintains the staggered entrances that produced a pointillistic texture at mm. 31-34, but they move at a much slower pace and the individual pitches have been recontextualized as long, sustained harmonics. These changes make it sound as though the

FIGURE 5 Section B, mm. 35-41.

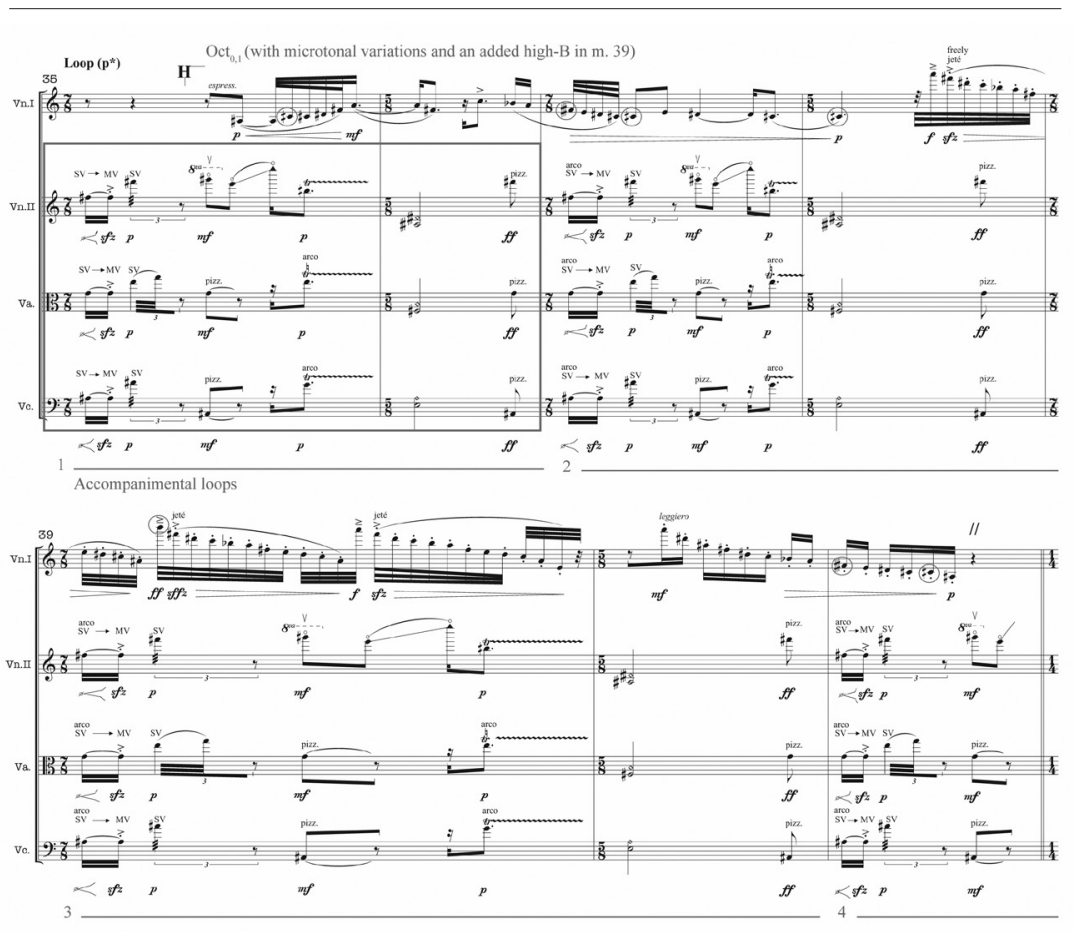


22. This technomorphic trope, in which material is modeled on tapelooping techniques, can be found in several of Di Castri's earlier works. In the aforementioned Lineage, a short two-bar loop repeats ten times before gradually dissolving through a combination of spectral filtering and orchestral cross-fading (mm. 181-206). And in the large multimedia work, Dear Life (2015), a seven-bar loop repeats five times before submitting to a subtractive process that gradually dismantles its musical inertia (mm. 165-209). original material from Section B has been temporally stretched and pitch shifted to a higher register, producing a ghostly aura that obscures the formal relationship between the two passages.

Returning to Section B, the first violin launches into a secondary theme at $\mathrm{m}$. 35, while the rest of the ensemble settles into a two-bar "loop" that repeats in a tape-like fashion. ${ }^{22}$ Shown in Figure 5, each of the harmonies within the loop is assigned a different articulation and dynamic level, offering a pocketsized compendium of the germinal sound characters presented at the outset of the work (dynamic swells, tremolos, glissandi, and pizzicati), as well as a few others that were introduced later in the piece (trills, harmonics). In total, the loop comprises six harmonies, the first and last of which are revoiced instances of the pitch class set (F-sharp, G, A-sharp), adding another level of circularity within the loop itself. On top of this repeating progression, the first violin plays a lyrical melody that provides a bit of forward momentum. Most of the violin's pitches belong to the $\mathrm{OCT}_{\mathrm{o}, 1}$ collection, with only a few exceptions; namely, a handful of microtonal pitches (C-quarter-sharp and F-three-quarters-sharp in the lower register), and the high B-natural in m. 39.

\section{Section C, mm. 80-142}

Excerpted in Figure 6, Section C features an intensive development of the quartet's initial glissando gesture. Interlocking in a hocket formation, the violins produce a cacophony of loud, double-stopped screeches that add a frenetic filigree to the dichotomous texture. Due to their use of excessive bow pressure and partially indeterminate pitch content, the violins project a rather muddled sense of harmony, but those pitches that are precisely notated comprise a complete whole tone collection $\left(\mathrm{WT}_{\mathrm{o}}\right)$. Pitted against the violins, the viola and cello embark on a forceful progression of trilled tetrachords that

FIGURE 6 Section C, mm. 98-102.

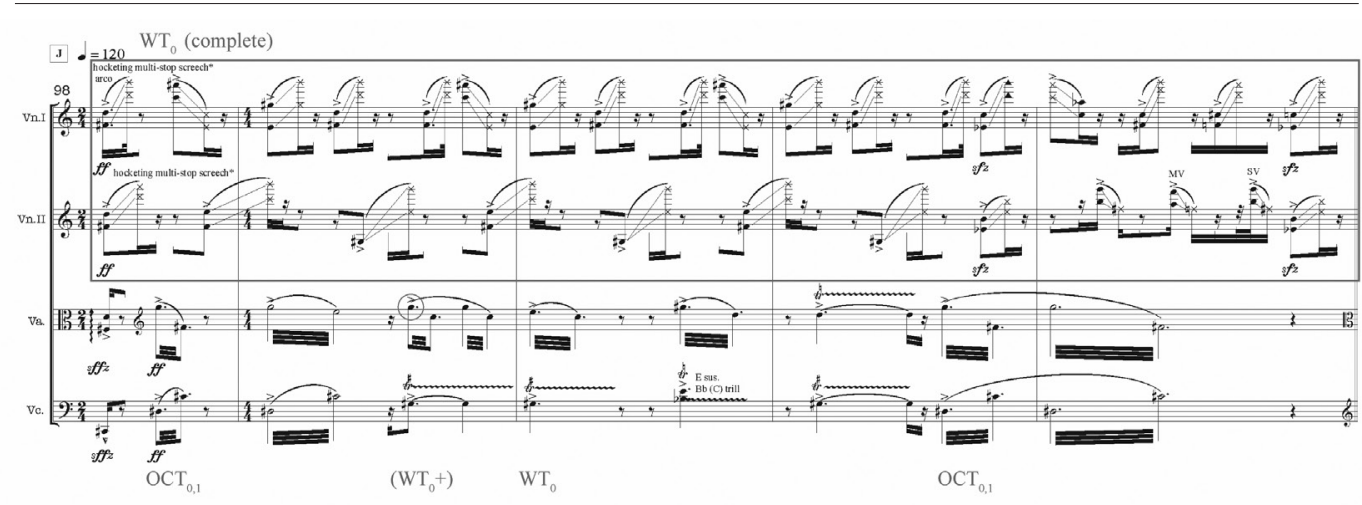


range in quality from octatonic subsets to pure whole tone sonorities. Taken together, the two halves of the quartet produce a heavy, fortissimo onslaught of noise and dissonance, marking a substantial escalation of musical tension as the work veers towards entropy. The section's prevailing sense of chaos and discontinuity is further enhanced by frequent parenthetical insertions of the quartet's refrain, shown in the next example.

FIGURE 7 Refrain, mm. 103-106.

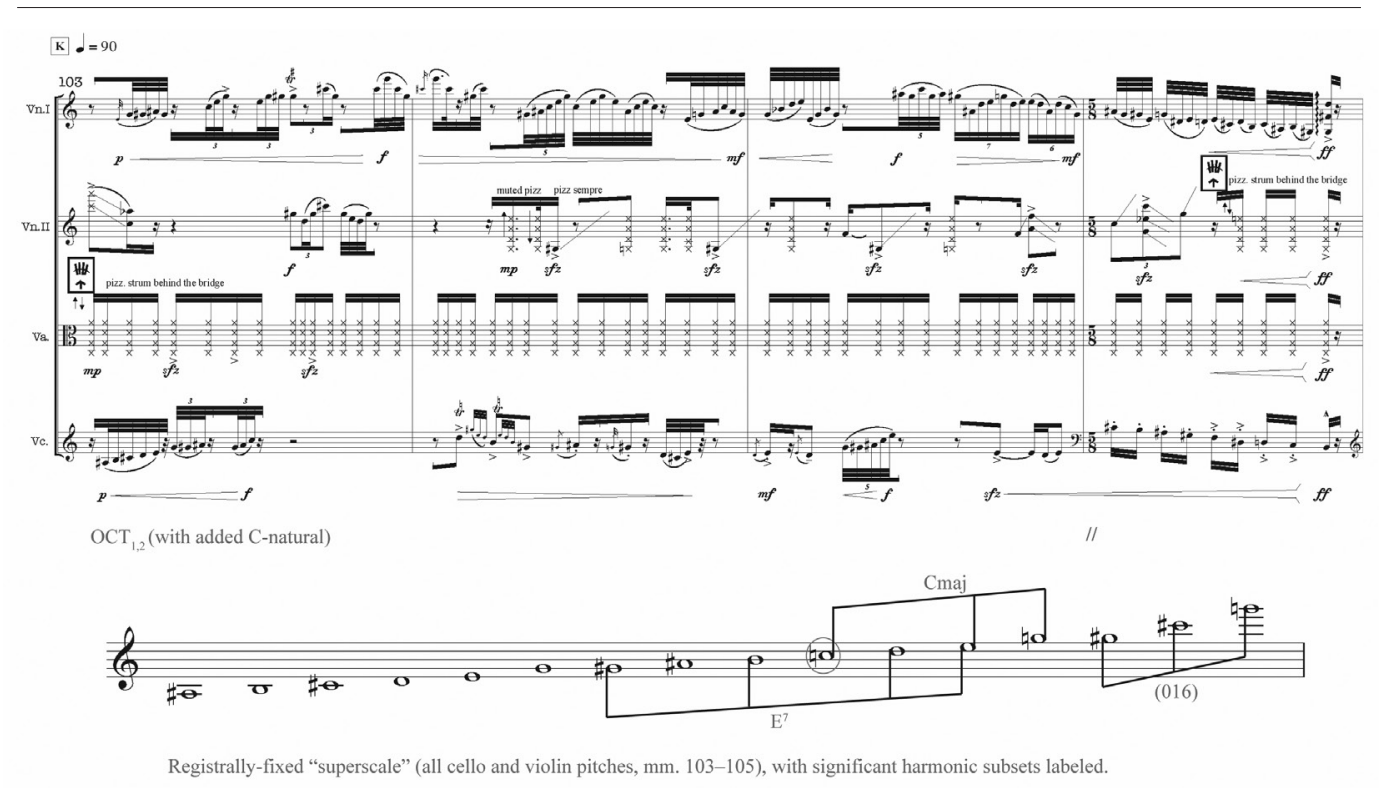

As the primary cause of the work's formal fragmentation, the quartet's refrain (Figure 7) acts as a disruptive module that criss-crosses the entirety of the work's form. Originally appearing in Section A (mm. 15-19), the refrain works its way into Section B (mm. 49-54), and then wreaks havoc in Section C by repeatedly interrupting the textural complex described above. The first interruption occurs in mm. 94-97 and is relatively contained, but the second interruption (starting at $\mathrm{m} .103$ ) extends along a side path that leads to a parenthetical climax at mm. 108-18. Following the interpolation of this highpoint, the primary material of Section $\mathrm{C}$ resumes with a climax of its own, pushing the quartet towards its outermost reaches of pandemonium.

As shown in Figure 7, there are three basic elements that constitute the core of the refrain: a) behind-the-bridge pizzicato strumming, b) short glissandi gestures, and c) dual melodic lines. The first two elements provide a static textural ground for the passage, while the dual melodic figurations 
intertwine to push the momentum forward. At each return, these separate strains of the refrain's texture rotate among the different instruments, but otherwise, they remain unchanged throughout their multiple iterations. The first violin and cello primarily move within an octatonic mode $\left(\mathrm{OCT}_{1,2}\right)$, with the important exception of $\mathrm{C}_{5}$, an anomaly that warrants further consideration. Looking closer, the melodies can be divided into different registral spans, within which the pitch content remains fixed. Because the density of pitches thins as the melodies ascend, certain segments seem to suggest alternative harmonic frameworks. Generally, the lower range expresses the octatonic mode, the middle range morphs into a vague sense of diatonicism (C-D-E-G, as well a prominent dominant seventh chord on E), and the upper range outlines pitch class set (o16) voiced as a perfect fourth and tritone combination (G-sharp-C-sharp-G). Due to this particular delineation, the combination of melodic pitches in the cello and violin produce a registrallyfixed "superscale" that maintains a general sense of octatonicism, while nesting within itself a flickering chain of subtle harmonic allusions.

At the end of the quartet (mm. 174-184), the refrain returns one last time, acting as a brief codetta to cap the work's overall form. In its final appearance, however, the intertwining melodic lines have been omitted, and in their stead, the prolonged whole tone harmonies from the beginning of the work return, combining with the pizzicato strumming and glissandi layers of the refrain texture. As a result, the two levels of the quartet's structure-the higher level of the work's primary sections (represented here by Section A) and the parenthetical level of the refrain-are sutured together in a fitting conclusion that provides a strong sense of formal closure.

\section{Conclusion}

As the preceding analysis shows, a formalist view of Di Castri's string quartet reveals the extent to which the work is shaped by defamiliarizing devices, which appear in a few different varieties: a) the juxtaposition or superimposition of contrasting materials, b) the transformation of musical ideas, and c) the distortion of linear form. These Shklovskian procedures are designed to sidestep the listener's habitual response mechanisms by repackaging familiar sounds in strange new guises. In essence, they prevent the music from congealing into a predictable æsthetic frame, forcing the listener out of complacency and into a more active engagement with the work's heterogeneous materials.

Expanding on this interpretation, it's possible to hear in the quartet a paral- 
on Kristeva's notion of a transgressive sujet en procès, we can hear the work as a subversion of established systems and a rejection of purist, monologic æsthetic ideologies. This interventionist reading of the work seems especially pertinent given the historical heft of the string quartet as a key genre in Western classical music. Tied to a long line of revered masterworks, the quartet has served as a rite of passage for nearly every major composer from the eighteenth century onwards. And throughout the twentieth century, it has been a fruitful site for radical innovation in the hands of composers such as Helmut Lachenmann or Brian Ferneyhough. Against the backdrop of this historical lineage, one hears Di Castri working within the bounds of an overdetermined medium, while at the same time challenging some of its basic assumptions in order to open up new avenues for personal creativity. A subversive impulse can be detected in her reappropriation of stringed instruments for the purpose of simulating technomorphic models, such as "fast-forwarded chatter," "reversed guitar attacks," and repeated "loops." Likewise, her inclusion of "folky" material mounts a challenge to the quartet's traditional locus on the high-classical side of Western music's popular/art divide. And finally, her construction of a discontinuous, nonlinear form simultaneously engages the familiar rondo scheme while recasting the functionary role of its refrain as an interruptive module, an intrusive force that repeatedly derails the work's forward momentum at unexpected moments. Through these and other deviations from established norms, Di Castri's String Quartet No. 1 enters into a carvnivalesque discourse which, as described by Kristeva, provides "the only space in which language escapes linearity (law) to live as drama in three dimensions. ${ }^{23}$ It is from within this discursive space that the work poses a challenge to the inherited strictures of the string quartet genre, destabilizing its æsthetic boundaries and forging new modes of expression within its wellworn sound palette. And on a much broader scale, it is from within this same fluid space of creativity that Di Castri and other composers of her generation are redrawing existing maps, reconfiguring both musical and social relations within the ever-expanding topography of today's new music landscape.

\section{B I B L I O G RAPHY}

BREcht, Bertolt ([1936]1964), "Alienation Effects in Chinese Acting," in John Willet (ed.), Brecht on Theatre: The Development of an Esthetic, New York, Hill and Wang, pp. 96-98.

Cameron, Allan (2008), Modular Narrative in Contemporary Cinema, New York, Palgrave Macmillan.

Di Castri, Zosha (2014), Whence We Come, Whither We Go: Return and Renewal in Lineage for Large Orchestra, PhD dissertation, Columbia University.

23. Kristeva, 1969, pp. 48-49. 
Grella-MożejKo, Piotr (2005), "Helmut Lachenmann-Style, Sound, and Text," Contemporary Music Review, vol. 42, n 1, pp. 57-75.

Grisey, Gérard (2008), “Vortex Temporum: 1994-1996," in Guy Lelong (ed.), Écrits ou L'Invention de la musique spectrale, Paris, Éditions MF, pp. 158-160.

KitTlen, Friedrich (1999), Gramophone, Film, Typewriter, Stanford, Stanford University Press.

Kramer, Jonathan D. (1981), "New Temporalities in Music," Critical Inquiry, vol. 7, n 3, pp. 539-556.

Kristeva, Julia ([1973]1986), “The System and the Speaking Subject,” in Toril Moi (ed.), The Kristeva Reader, Oxford, Basel Blackwell, pp. 24-33.

Kristeva, Julia ([1969]1986), “Word, Dialogue, and Novel," in Toril Moi (ed.), The Kristeva Reader, Oxford, Basel Blackwell, pp. 34-61.

Lachenmann, Helmut (2003), "Hearing [Hören] is Defenseless-Without Listening [Hören]: On Possibilities and Difficulties," Circuit, musiques contemporaines, vol. 13, nº 2, pp. 27-50.

Leroux, Philippe (2006), "The Model of the Model in VOI(REX)," in Carlos Agon et al. (eds.), The OM Composer's Book, v. 2, Paris, Delatour, pp. 149-164

Serafini, Luigi (1981), Codex Seraphinianus, New York, Abbeville Press.

SHKLOvSKY, Viktor ([1917]1965), "Art as Technique," in Lee T. Lemon and Marion J. Reis (eds.), Russian Formalist Criticism: Four Essays, Lincoln, University of Nebraska Press.

Shкlovsky, Viktor ([1921]1965), "Sterne's Tristram Shandy: Stylistic Commentary," in Lee T. Lemon and Marion J. Reis (eds.), Russian Formalist Criticism: Four Essays, Lincoln, University of Nebraska Press.

Wilson, Peter Niklas ([1989]2000), "Vers une ‘écologie des sons': Partiels de Gérard Grisey et l'esthétique du groupe de l'Itinéraire," Analyse Musicale, $3^{\mathrm{e}}$ trimestre, pp. 36-52.

\section{SCORES}

Di Castri, Zosha (2015), Dear Life, self-published score.

Di Castri, Zosha (2013), Lineage, self-published score.

Di Castri, Zosha (2012), Phonotopographie, self-published score.

Di Castri, Zosha (2014), Serafiniana, self-published score.

Di Castri, Zosha (2016; rev. 2017), String Quartet No. 1, self-published score. 